\title{
Applying Quality Measures and Guidelines in the Management of Acute Coronary Syndrome and Venous Thromboembolism Introduction
}

\author{
Michael P. Gulseth, PharmD, BCPS
}

A cute coronary syndrome (ACS) (ST-segment elevation myocardial infarction [STEMI], non-ST-segment elevation myocardial infarction [NSTEMI]) and unstable angina and venous thromboembolism (VTE) (deep vein thrombosis, pulmonary embolism [PE]) are 2 common conditions causing considerable morbidity and mortality that have a large economic impact in the United States. Heart disease continues to be the leading cause of death in both sexes. More specifically, the incidence of coronary heart disease (CHD) is staggering. For men, $22.8 \%$ of those aged 60-79 years have a diagnosis of CHD, and $32.7 \%$ of those aged $\geq 80$ years carry the diagnosis. ${ }^{1}$ For women, $15.4 \%$ aged between 60 and 79 years carry a diagnosis of CHD, and $21.6 \%$ of those aged $\geq 80$ years carry the diagnosis. The incidence of myocardial infarction (MI) continues to be substantial, with nearly 800,000 Americans having had a diagnosed MI by the time they are aged $\geq 65$ years. ${ }^{1}$

The prevalence of CHD increases with age, and the number of Americans with CHD is expected to increase as the population ages. ${ }^{1}$ Patients who survive MI are at increased risk for recurrent MI, angina pectoris, heart failure, stroke, and sudden death. ${ }^{1}$

In 2008, the estimated direct and indirect costs of CHD in the United States are $\$ 151.6$ billion. ${ }^{1}$ This amount is considerably higher than the estimated costs for stroke ( $\$ 62.7$ billion), hypertensive disease ( $\$ 66.4$ billion), and heart failure ( $\$ 33.2$ billion). ${ }^{1}$

More than 600,000 Americans develop symptomatic VTE each year, and another 300,000 Americans die of VTE yearly. ${ }^{2}$ The rate of recurrence of VTE is high (17\% after 2 years), so prevention of recurrence is an important strategy in managing VTE. ${ }^{3}$ VTE has been referred to as a silent disease because it is often asymptomatic; therefore, prevention is critical because sudden death can be the first "symptom." Pulmonary hypertension and post-thrombotic syndrome (a painful chronic condition characterized by leg swelling, skin induration, and sometimes

J Manag Care Pharm. 2008;14(6)(suppl S-a):S2-S3

Copyright@ 2008, Academy of Managed Care Pharmacy. All rights reserved.

\section{Author}

MICHAEL P. GULSETH, PharmD, BCPS, at the writing of this article, was Assistant Professor at the University of Minnesota College of Pharmacy in Duluth.

AUTHOR CORRESPONDENCE: Michael P. Gulseth, PharmD, BCPS, Assistant Professor, University of Minnesota College of Pharmacy, Duluth, 127 Life Science, 1110 Kirby Dr., Duluth, MN 55811.

Tel.: 218.726.6012; Fax: 218.726.6500; E-mail: mgulseth@umn.edu venous stasis ulcers) are common long-term consequences of VTE. ${ }^{4,5}$ Annually, 800,000 patients will develop post-thrombotic syndrome. ${ }^{5,6}$ Estimated annual costs of hospitalization and follow-up treatment for patients with VTE is $\$ 1.5$ billion in the United States. ${ }^{7}$ Overall, appropriate management of ACS and VTE is a concern because of the high morbidity, mortality, and costs associated with these conditions. Fatal PE may be the most common preventable cause of hospital death. ${ }^{8}$

Anticoagulant therapies play an important role in the management of ACS and VTE. Problems with anticoagulation therapies and avoidable morbidity and mortality caused by VTE have prompted the federal government and various national organizations concerned with health care quality to focus attention on the proper use of anticoagulant therapies for the prevention and treatment of VTE and management of ACS. These organizations include the Leapfrog Group, National Quality Forum (NQF), The Joint Commission (JC), Agency for Healthcare Research and Quality, and the American Public Health Association. The 2 organizations whose efforts should be noted here are the NQF and The JC.

The NQF is a public-private, not-for-profit organization created to develop and implement a national strategy for health care quality measurement and reporting. The JC (formerly known as the Joint Commission on Accreditation of Healthcare Organizations, or JCAHO) is an independent, not-for-profit organization that establishes standards and accredits hospitals and other health care facilities with the goal of improving the quality and safety of care provided by these institutions. The NQF and The JC are collaborating to develop national consensus standards for the prevention and care of VTE. ${ }^{9}$ These standards address VTE prevention, treatment, and outcomes. The prevalence, morbidity, mortality, and risk factors associated with VTE are reviewed in the second article titled "Guidelines and Performance Measures for the Prevention and Treatment of Venous Thromboembolism." Rates of adherence to evidence-based guidelines for VTE prophylaxis and treatment, as well as efforts to raise awareness and address the problem of VTE, including strategies to promote VTE prophylaxis, also are discussed. Further, optimal treatment of VTE is reviewed.

The Surgical Care Improvement Project (SCIP) is a national hospital-based quality improvement initiative led by the Centers for Medicare \& Medicaid Services (CMS) to reduce the rate of adverse outcomes from common surgical procedures, including VTE. ${ }^{10}$ The proper use and timing of VTE prophylaxis before surgery and the incidence of VTE during or within 30 days after surgery are among SCIP measures. ${ }^{11}$ Reporting data for these measures to the CMS by health care institutions will be required 


\section{Applying Quality Measures and Guidelines in the Management of Acute Coronary Syndrome and Venous Thromboembolism Introduction}

to obtain full reimbursement from the CMS. The data also will become part of Hospital Compare, a CMS database designed to allow consumers to compare the quality of care provided at various health care institutions.

Evidence-based guidelines are available from the American College of Chest Physicians (ACCP) for the prevention and treatment of VTE, as well as the American College of Cardiology (ACC) and the American Heart Association (AHA), for the management of ACS.12-15 Recent updates to the ACS guidelines from the ACC/AHA reflect the results of recent studies comparing therapeutic regimens involving antiplatelet and anticoagulant therapies. ${ }^{16,17}$ Revised guidelines from the ACCP for the use of antithrombotic therapy were recently published. The first article in this supplement titled "Guidelines and Performance Measures for the Management of Acute Coronary Syndrome" characterizes the pathophysiology of ACS and describes the ACC/AHA guidelines for reperfusion therapy in patients with STEMI; the use of antiplatelet and anticoagulant therapies for the treatment of STEMI, NSTEMI, and unstable angina, including patients who undergo percutaneous coronary intervention; and long-term antiplatelet therapy after an ACS episode.

The development of national quality improvement initiatives designed to improve VTE prophylaxis and the use of antiplatelet and anticoagulant therapies along with the recent changes in evidence-based guidelines for the management of ACS have important implications for managed care pharmacists. For example, managed care plan benefits should be designed to optimize the use of drug therapies to minimize the morbidity, mortality, and costs associated with these common conditions. In addition, managed care pharmacists can use various strategies to improve quality of care and clinical outcomes and also reduce costs in patients with ACS and VTE by improving clinician adherence to evidence-based treatment guidelines and patient adherence to the treatment plan. The third article titled "Management of Acute Coronary Syndrome and Venous Thromboembolism: A Managed Care Perspective" discusses the economic impact of ACS and VTE and highlights factors that contribute to preventable morbidity, mortality, and costs associated with these conditions. Strategies that managed care pharmacists can use to improve clinician adherence to evidence-based treatment guidelines and patient adherence to the treatment plan, thereby improving clinical and economic outcomes, are also addressed.

\section{REFERENCES}

1. American Heart Association/American Stroke Association. Heart disease and stroke statistics-2008 update: a report from the American Heart Association Statistics Committee and Stroke Statistics Subcommittee. Available at: www.americanheart.org/downloadable/heart/1200082005246HS_Stats\%20 2008.final.pdf. Accessed March 10, 2008.

2. Heit JA, Cohen AT, Anderson Jr FA, on behalf of the VTE Impact Assessment Group. Estimated annual number of incident and recurrent, non-fatal and fatal venous thromboembolism (VTE) events in the U.S. Blood. 2005; 106:abstract 910. Available at: http://abstracts.hematologylibrary.org/cgi/ content/abstract/106/11/910? maxtoshow $=\& H I T S=10 \&$ hits=10\&RESULT
FORMAT=l\&authorl=Heit+J\&andorexacttitle=and\&andorexacttitleabs= and\&andorexactfulltext $=$ and $\&$ searchid $=1 \&$ FIRSTINDEX $=10 \&$ sortspec $=$ relevance\&resourcetype=HWCIT. Accessed March 10, 2008

3. Prandoni P, Villalta S, Bagatella P, et al. The clinical course of deep-vein thrombosis. Prospective long-term follow-up of 528 symptomatic patients. Haematologica. 1997;82:423-28.

4. Pengo V, Lensing AW, Prins MH, et al. Incidence of chronic thromboembolic pulmonary hypertension after pulmonary embolism. N Engl J Med. 2004;350:2257-64.

5. Kahn SR, Solymoss S, Lamping DL, et al. Long-term outcomes after deep vein thrombosis: postphlebitic syndrome and quality of life. J Gen Intern Med. 2000;15:425-29

6. Brandjes DP, Buller HR, Heijboer H, et al. Randomised trial of effect of compression stockings in patients with symptomatic proximal-vein thrombosis. Lancet. 1997;349:759-62.

7. Anderson Jr FA, Wheeler HB, Goldberg RJ, et al. A population-based perspective of the hospital incidence and case-fatality rates of deep vein thrombosis and pulmonary embolism. The Worcester DVT Study. Arch Intern Med. 1991;151:933-8.

8. American Public Health Association. Deep-vein thrombosis: advancing awareness to protect patient lives. February 26, 2003. Available at: www. apha.org/NR/rdonlyres/A209F84A-7C0E-4761-9ECF-61D22E1E11F7/0/ DVT_White_Paper.pdf. Accessed March 10, 2008.

9. The Joint Commission. National consensus standards for prevention and care of venous thromboembolism (VTE). Available at: www. jointcommission.org/PerformanceMeasurement/PerformanceMeasurement/ VTE.htm. Accessed March 10, 2008.

10. MedQIC. SCIP project information. Available at: www.medqic.org/dcs/ ContentServer?cid $=1122904930422 \&$ pagename $=$ Medqic $\% 2$ FContent $\%$ 2FParentShellTemplate\&parentName=Topic \&c=MQParents. Accessed March 10, 2008.

11. MedQIC. Measures: venous thromboembolism. Available at: www. medqic.org $/ \mathrm{dcs} /$ ContentServer?cid $=1137448680860 \&$ pagename $=$ Medqic $\% 2 \mathrm{~F}$ Measure\%2FMeasuresHome\&parentName=Topic\&level3=Measures\&c= MQParents. Accessed March 10, 2008.

12. Geerts WH, Pineo GF, Heit JA, et al. Prevention of venous thromboembolism: the Seventh ACCP Conference on Antithrombotic and Thrombolytic Therapy. Chest. 2004;126(3 suppl):338S-400S.

13. Büller HR, Agnelli G, Hull RD, et al. Antithrombotic therapy for venous thromboembolic disease: the Seventh ACCP Conference on Antithrombotic and Thrombolytic Therapy. Chest. 2004;126(3 suppl):401S-28S.

14. Anderson JL, Adams CD, Antman EM, et al. ACC/AHA 2007 guidelines for the management of patients with unstable angina/non ST-elevation myocardial infarction: a report of the American College of Cardiology/ American Heart Association Task Force on Practice Guidelines. Circulation. 2007;116:e148-304.

15. Antman EM, Hand M, Armstrong PW, et al. 2007 Focused Update of the ACC/AHA 2004 Guidelines for the Management of Patients with ST-Elevation Myocardial Infarction: a report of the American College of Cardiology/ American Heart Association Task Force on Practice Guidelines. Circulation. 2008;117:296-329.

16. Grines CL, Bonow RO, Casey Jr DE, et al. Prevention of premature discontinuation of dual antiplatelet therapy in patients with coronary artery stents: a science advisory from the American Heart Association, American College of Cardiology, Society for Cardiovascular Angiography and Interventions, American College of Surgeons, and American Dental Association, with representation from the American College of Physicians Circulation. 2007;115:813-18.

17. King III SB, Smith Jr S, Hirshfeld Jr JW, et al. 2007 Focused update of the ACC/AHA/SCAI 2005 guideline update for percutaneous coronary intervention: a report of the American College of Cardiology/American Heart Association Task Force on Practice Guidelines: 2007 Writing Group to Review New Evidence and Update the ACC/AHA/SCAI 2005 Guideline Update for Percutaneous Coronary Intervention, writing on behalf of the 2005 Writing Committee. Circulation. 2008;117:261-95. 